\title{
FORUM
}

\section{The Rotterdam Approach Control}

\author{
R. B. Richardson
}

Listening to Captain Brandenburg's talk on his ideas about the future navaids in Rotterdam (this Journal, 25, 67) I was left with the conviction that even the most ardent opponents of change will at least be better informed having heard it. Although in his introduction he excluded direct reference to Rotterdam, it is well known that the new Auto Com/Radar Data system when introduced there will be a real milestone for historians of port entrance techniques. I would like to think that it will lead us in this country one step closer to the day when we take the option out of progress on our own coasts and waterways and get on with it as they are doing in Rotterdam. There is of course one great differencein Holland and Germany the Governments and Municipalities are involved, so that the necessary finances are seen in a clearer light.

As so often in other fields, the Dutch have made a massive investment in innovation. While we in this country, and especially in London, have been thinking about it, and some presuming to talk about it, they have got on with it and arrived at the new frontier. Whether we like it or not, and whatever the overkill attitudes of convention may say, we can only react while they have acted. Somehow they seem to have overcome the obsession against technology so often heard here, whether by Admiralty Courts and their advisers or the conventions of London. Some of these seem to be frozen for life to a set of conclusions that are no longer alive. Rotterdam has reached the interface between such conventions and the ultimate way ahead; the world will watch with profound interest.

Why should we show such unease at the aids of high technology, whether hardware, software or plain live-ware ? The surgeon is not afraid of the X-ray or the laser-in fact he sometimes depends on them. The bogey of expense is often a red herring; there are many precedents to show that economics are not always what the pessimists forecast. From my older long-haul communications days, I am well aware of the fact that never since the first transatlantic telephone cable was laid was it possible for the operators to reduce the cable rate-until the satellites got up into orbit. Since then they have been reduced no less than three times. This is one example of the highest technology reducing costs to society. It may even be cheaper to navigate on the coasts or approaches by satellite in some total transport systems and trades. How are we likely to react to that, if society calls for it?

I am sure Brandenburg's vision of the likely future will be quite near the mark. He already accepts such inevitabilities as allocation of entrance and departure numbers so that optimum sequences can be maintained. Here in London in spite of realistic pressures some people still think that only the Master can say what sequence he ought to maintain. In the new Rotterdam system the ship is. fed with automated position information by electronic means, without human interpretation or intervention, and will obviously be expected to act on this. $\mathrm{He}$ 
referred to the work of the College of Technology in Liverpool in conjunction with ourselves in London River and supported by the National Ports Council. The computer programme for the model port is based on the conditions obtaining in London and its approaches, and has been shown to be a perfectly viable programme which has worked very well on our main P.L.A. computer during simulated and live traffic comparison runs.

We need to disengage the straight hardware of Brandenburg's subject from the natural interest that surrounds it to see the true meaning of the new look in philosophy that it introduces to the marine stage; another Brandenburg concerto and a welcome sound.

His comments on legislative means were perhaps over simplified, for this brings us face to face with some of the oldest conventions known to man. A lot of case law and mumbo-jumbo will have to be cleared away first. Admiralty Courts have only accepted decisions reached by the man, albeit helped by various aids. Now they will have to accept that the man is monitoring the black box and acting on its directions. If these are truth, measured and quantified, how can he reasonably do otherwise? For some time this has been the situation for aircraft, - so can the patriachs claim that the sea captain is all that different in culture and intelligence from the air captain; his run up to the waterway is exactly analogous to the glide path of the aircraft; the flare-out in each case is left to the man in charge. Yet some people go to great pains to repeat that there is no similarity at all between ship and aircraft movements and safety. The inhibitions of the one are often the opportunities of the other, but no rational thinking can rule out any similarity at all on that count: the aircraft can climb, the ship cannot; the aircraft cannot stop, the ship often can; and so forth. I believe that the philosophies of the two modes of transport are entirely compatible; both in reality require no more than traffic management or control as Brandenburg calls it. The safety of air traffic does not depend very much on the third dimension we hear so much about-it depends on precise order and conformity within established lanes and corridors. It would seem that the only time the air traffic people get into real trouble is precisely when they are using the third dimension, when they are descending or climbing in or out of terminal areas. There is a lesson here, for those who want to learn it, in the sea context and the world cries out for it. Only convention holds us back and it seems to me that the marine side is now going through precisely the same argument that the air traffic people went through in the late forties and fifties. What are we going to do about it?

\title{
Navigational Discipline at Sea
}

\author{
Captain P. A. Thompson
}

Ir is doubtful if at any period in the history of seafaring a greater effort has been made to organize the safe conduct of ships about the seas than that which is being made today, and it is equally doubtful if the need was ever more urgent. At the present time a large amount of thought and work is being put into the task of trying to formulate rules and systems aimed at providing for the safer navigation of vessels at sea. Excellent ideas have been proposed for conduct in traffic, such 